\title{
Performance of High-k Dielectric Material for Short Channel Length MOSFET Simulated using Silvaco TCAD Tools
}

\author{
Fatin Antasha Anizam, Lyly Nyl Ismail, Norsabrina Sihab and Nur Sa'adah Mohd Sauki
}

\begin{abstract}
Short channel effect (SCE) occur in the MOSFET devices when the oxide layer became thinner, and the gate length become shorter. The purposed of this study is to find a new dielectric and gate material to replace the conventional oxide which is silicon dioxide $\left(\mathrm{SiO}_{2}\right)$ and polysilicon as gate material. The objective of this study is to investigate the performance of MOSFET using different types of high-k dielectric material and germanium $(\mathrm{Ge})$ as gate material. The MOSFET structure was fabricated and simulated using Silvaco TCAD tool. The overall performance of the MOSFET is evaluated based on the currentvoltage (I-V) characteristics. Result show that MOSFET fabricated with $\mathrm{HfO}_{2}$ and $\mathrm{Ge}$ as dielectric and gate material has high drive current reduce leakage current by a factor of 0.55 from the conventional MOSFET. Therefore, combination of $\mathrm{HfO}_{2}$ and Ge in MOSFET structure has the best performance compared to $\mathrm{SiO}_{2}$ and polysilicon because it produces smaller leakage current and smaller $V_{\text {th }}$ when shrinking the device sizes, hence reducing SCEs.
\end{abstract}

Index Terms-Dielectric material, High-k, short channel effect, threshold voltage.

\section{INTRODUCTION}

$\mathrm{T}$ HE process to diminish the size of MOSFET devices have been control the technology for about three decades and it seems that this trend will continue for many more years [1]. The demands to scale down the channel length comes from DRAM industry as they want to reduce the cost [2].

This manuscript is submitted on 22th June 2021 and accepted on 25th August 2021. Fatin Antasha Anizam is with the School of Electrical Engineering, College of Engineering, University Teknologi MARA Cawangan Pulau Pinang, MALAYSIA (e-mail: antashafatin@gmail.edu.my).

Lyly Nyl Ismail is with the School of Electrical Engineering, College of Engineering, University Teknologi MARA Cawangan Pulau Pinang, MALAYSIA (e-mail: lylynyl814@uitm.edu.my).

Norsabrina Sihab is with the School of Electrical Engineering, College of Engineering, University Teknologi MARA Cawangan Pulau Pinang, MALAYSIA (e-mail: norsabrina@uitm.edu.my).

Nur Sa'adah Mohd Sauki is with the School of Electrical Engineering, College of Engineering, University Teknologi MARA Cawangan Pulau Pinang, MALAYSIA (e-mail: norsabrina@uitm.edu.my).

1985-5389/C 2021 The Authors. Published by UiTM Press. This is an open access article under the CC BY-NC-ND license (http://creativecommons.org /licenses/by-nc-nd/4.0/).
Since 1960, silicon dioxide $\left(\mathrm{SiO}_{2}\right)$ have been used as dielectric materials in microelectronics industry [1]. The gate oxide has been continuously scaled down from days to days as rapidly growth of technology in transistor and integrated circuits technology. Today, the gate oxide has been successfully shrinking up to $1.5 \mathrm{~nm}$ thick [2].

Shrinking the size of MOSFET will make the source and drain move closer to the gate. When the gate voltage, $V_{G}$ are larger than source-drain voltage, $\mathrm{V}_{\mathrm{DS}}$, channel or path is created for electron and holes to move from source to drain [3]. Nevertheless, keep increasing $V_{\mathrm{G}}$, it causes drain and source to move more closer to gate and causes short channel effect (SCEs) to occur. SCEs will interfere the current flow and potential distributions of MOSFET hence worsen the performances. Some of the limitations to narrowing the size of devices is gate insulator scaling, shallow junction technology, SCEs and off-state leakage current in MOSFET devices. Varied dielectric thickness and channel length can reduce the device's size but leading to tunnelling leakage current between source and drain [4]. In addition, there are several disadvantages of using $\mathrm{SiO}_{2}$ as dielectric material. $\mathrm{SiO}_{2}$ have limited maximum capacitance and tunnelling current leakage increases if the thickness of $\mathrm{SiO}_{2}$ decreased [5]. Consequently, to designs smaller or ultra-thin MOSFET, many things should be considered such as dielectric material.

High-k material is suggested to replace $\mathrm{SiO}_{2}$ in this study to overcome the SCEs issue. The purpose of using high-k material is because it has low interface state density and good thermal stability [6]. I-V characteristics of MOSFET such as threshold voltage, $\mathrm{V}_{\text {th }}$, drive current, $\mathrm{I}_{\mathrm{ON}}$ and leakage current, $\mathrm{I}_{\mathrm{OFF}}$ are the parameter that affected when changing the dielectric material because its value depends on the value of the dielectric constant and the thickness of the dielectric layer. With high value of dielectric constant, the thickness of the dielectric or oxide layer can be modified so that the I-V characteristic can be enhanced $[7,8]$. Table 1 below summarized some high-k material that compatible with silicon $(\mathrm{Si})$ substrate which has high dielectric constant, $k$ and high energy band gap, $E_{g}$. Hafnium oxide $\left(\mathrm{HfO}_{2}\right)$ were selected to use a new dielectric material because it has the high dielectric constants $\sim 22$, high energy gap, $\mathrm{E}_{\mathrm{g}}$ in the range of $4.5 \sim 6.0 \mathrm{eV}$, high $\mathrm{I}_{\mathrm{ON}}$ and low $\mathrm{I}_{\mathrm{OFF}}$. 
Other researcher suggested by changing the material use to fabricate gate from polysilicon to metal can also enhance mobility and reduce leakage current in MOSFET device, hence increased the device performance. This is because metal has lower value of $E_{g}$. Germanium (Ge) are proposed in this study to replace polysilicon because Ge has energy bandgap for around $0.6 \mathrm{eV}$ while polysilicon is $1.1 \mathrm{eV}$ [9].

TABLE I

PROPERTIES OF HiGH-K Dielectric MATERIAL

\begin{tabular}{cccc}
\hline \hline MATERIAL & $\begin{array}{c}\text { DiELECTRIC } \\
\text { CONSTANT, K }\end{array}$ & $\begin{array}{c}\text { Energyband } \\
\text { gap, Eg (eV) }\end{array}$ & Offset Eg (eV) \\
\hline $\mathrm{SiO}_{2}$ & 3.9 & $8.9 \sim 9.0$ & $3.0 \sim 3.5$ \\
$\mathrm{Si}_{3} \mathrm{~N}_{4}$ & 7.9 & $5.0 \sim 5.3$ & $2.0 \sim 2.4$ \\
$\mathrm{Al}_{2} \mathrm{O}_{3}$ & 9.5 & $5.6 \sim 9.0$ & $2.78 \sim 3.5$ \\
$\mathrm{HfO}_{2}$ & 22 & $4.5 \sim 6.0$ & 1.5 \\
& & & \\
\hline \hline
\end{tabular}

Therefore, the objective of this study is to overcome the SCEs in MOSFET fabricate with $\mathrm{SiO}_{2}$ and polysilicon as dielectric and gate material. This study was to investigate the performance of MOSFET fabricate with high-k dielectric $\left(\mathrm{HfO}_{2}\right)$ and $\mathrm{Ge}$ as new dielectric and gate material, respectively. The performance of the new structure MOSFET $\left(\mathrm{HO}_{2}\right.$ and $\left.\mathrm{Ge}\right)$ is evaluated based on the I-V characteristics. The result of a new structure MOSFET was compared with conventional MOSFET that use $\mathrm{SiO}_{2}$ and polysilicon. The fabrication of MOSFET structure was simulated using Silvaco TCAD tool where Athena was used to produce the MOSFET structure and ATLAS to investigate the device performance which is the I-V characteristics.

\section{Methodology}

\section{A. MOSFET Device Structure}

There are two type of MOSFET structure are simulated using Silvaco TCAD tool as shown on Fig.1. First MOSFET structure using $\mathrm{SiO}_{2}$ and polysilicon as dielectric and gate material, respectively and second structure of MOSFET using high-k and $\mathrm{Ge}$ as dielectric and gate material, respectively. Thickness of oxide layer, $t_{0 x}$ and channel length, $\mathrm{L}_{\mathrm{g}}$ was varied to investigate the I-V characteristic which focus on threshold voltage, $V_{\text {th }}$, drive current, ION and leakage current, IOFF. The performance of MOSFET was compared to investigate which one have the best performances. Athena were used to create a two-dimensional (2D) MOSFET structure. The parameter properties used to create the MOSFET structure are tabulate in Table 2.

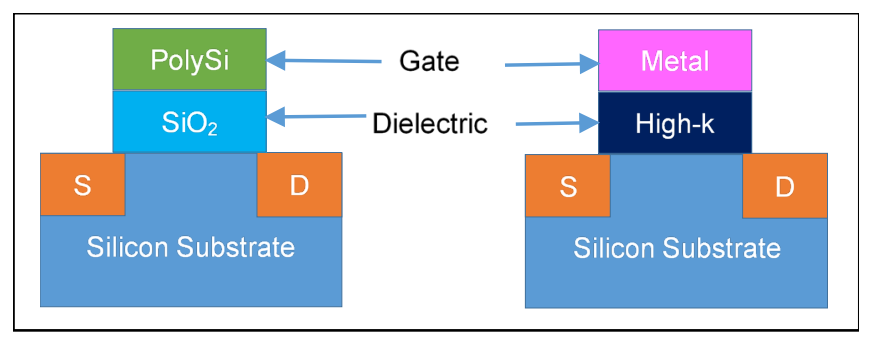

Fig. 1. MOSFET structure (a) $\mathrm{SiO} 2$ as dielectric material (b) High-k as dielectric material.
TABLE II

PARAMETER FOR NMOS STRUCTURE

\begin{tabular}{lll}
\hline \hline \multicolumn{1}{c}{ PARAMETER } & \multicolumn{1}{c}{$\begin{array}{c}\text { MOSFT WITH POLYSI } \\
\text { AS GATE }\end{array}$} & \multicolumn{1}{c}{$\begin{array}{c}\text { MOSFT with Ge as } \\
\text { Gate }\end{array}$} \\
\hline Acceptor doping & $1 \times 10^{20}$ & $2.02 \times 10^{12}$ \\
$\begin{array}{l}\text { Donor doping } \\
\text { Substrate / } \\
\text { channel doping }\end{array}$ & $1 \times 10^{20}$ & $2.02 \times 10^{12}$ \\
1) Dielectric gate & $\mathrm{SiO}_{2}, \mathrm{Al}_{2} \mathrm{O}_{3}, \mathrm{Si}_{3} \mathrm{~N}_{4}$, & $\mathrm{HfO}_{2}$ \\
& $\mathrm{HfO}_{2}$ & \\
2) Substrate & $\mathrm{Si}$ & $\mathrm{Si}$ \\
3) Source & $\mathrm{Al}$ & $\mathrm{Al}$ \\
4) Gate & $\mathrm{PolySi}$ & $\mathrm{PolySi} \& \mathrm{Ge}$ \\
5) Drain & $\mathrm{Al}$ & $\mathrm{Al}$ \\
& & \\
\hline \hline
\end{tabular}

\section{B. ATLAS Simulator}

ATLAS has been used to analyse the electrical behaviour in MOSFET structure. It consists of a few files, which are text file, $\log$ file and structure file. All the command was written in text file. Structure file store all 2D data related with value of solution and defines all the structure that was simulated. Tony plot is the visualization tool that comprehensives to view and analyse simulator output [11]. In this study, it was used to generate the result and graph of $\mathrm{I}-\mathrm{V}$ characteristics such as drain current vs gate voltage $\left(I_{D}-V_{G}\right)$, drain current vs drain voltage, $\left(I_{D}-V_{D}\right)$, threshold voltage, $\mathrm{V}_{\text {th }}$, drive current, $\mathrm{I}_{\mathrm{ON}}$ and leakage current, $\mathrm{I}_{\mathrm{OFF}}$. Table 3 summarized the list of coding used in ATLAS to extract the $\mathrm{I}_{\mathrm{D}}-\mathrm{V}_{\mathrm{G}}$ and $\mathrm{I}_{\mathrm{D}}-\mathrm{V}_{\mathrm{D}}$.

TABLE III

PROPERTIES OF High-K DieleCtric MATERIAL

\begin{tabular}{|c|c|c|}
\hline Symbol & Coding & Explaination \\
\hline 1 & $\begin{array}{l}\text { solve init } \\
\text { solve vdrain }=0.05 \\
\text { solve vdrain }=0.1 \\
\text { solve vdrain }=0.2 \\
\text { solve vdrain }=0.5 \\
\text { log oufile }=\text { sio } 2 . \log \\
\text { solve vgate }=0 \text { vstep }=0.05 \\
\text { vfinal }=1 \text { name }=\text { gate } \\
\text { tonyplot sio } 2 . \log \text { sio } 2 . \text { net }\end{array}$ & $\begin{array}{l}\text { Set drain biases and } \mathrm{I}_{\mathrm{D}}-\mathrm{V}_{\mathrm{G}} \\
\text { graph was plotted on } \\
\text { Tonyplot }\end{array}$ \\
\hline 2 & $\begin{array}{l}\text { solve init } \\
\text { solve vgate=3.3 } \\
\text { outf }=\text { solve_hfo } 21 \text { um } \\
\text { load infile=solve_hfo } 21 \mathrm{um} \\
\text { log outf }=\text { hfo } 21 \text { um.log } \\
\text { solve name=drain vdrain=0 } \\
\text { vfinal }=3.3 \\
\text { vstep }=0.3\end{array}$ & $\begin{array}{l}\text { Set gate biases and } I_{D}-V_{D} \\
\text { graph was plotted on } \\
\text { Tonyplot }\end{array}$ \\
\hline
\end{tabular}

\section{RESULTS AND DISCUSSION}

The performance of MOSFET structure on $\mathrm{V}_{\text {th }}$, leakage current and $I_{D}-V_{G}$ and $I_{D}-V_{D}$ characteristics can be investigated by vary thickness of oxide, $\mathrm{t}_{\mathrm{ox}}$ layer and vary channel length, $\mathrm{L}_{\mathrm{g}}$.

\section{A. Fabrication of MOSFET structure}

Figure 2 show the two types of MOSFET structure that was simulated using ATHENA. Figure 2(a) show the $1^{\text {st }}$ MOSFET structure with $\mathrm{SiO}_{2}$ and polysilicon as dielectric and gate 
material while Fig. 2(b) show the $2^{\text {nd }}$ MOSFET structure with $\mathrm{HfO}_{2}$ and $\mathrm{Ge}$ as dielectric and gate material. For both structure the oxide thickness, $t_{o x}$ and channel length was set to be fixed values which is $t_{o x}$ is $10 \mathrm{~nm}$ and $L_{g}$ is $1.0 \mathrm{um}$ because these two values are the maximum value for $\mathrm{SiO}_{2}$ as dielectric. Above these values, MOSFET with $\mathrm{SiO}_{2}$ start showing the degradation in device performance due to SCEs effect.

Once the MOSFET structure are constructed, the extract data for $I-V$ characteristics which is $I_{D}-V_{D}$ and $I_{D}-V_{G}$ can be obtained. From the $\mathrm{I}_{\mathrm{D}}-\mathrm{V}_{\mathrm{D}}$ and $\mathrm{I}_{\mathrm{D}}-\mathrm{V}_{\mathrm{G}}$, data for $\mathrm{V}_{\text {th }}$, $\mathrm{I}_{\mathrm{ON}}$ and $\mathrm{I}_{\mathrm{OFF}}$ can be obtained. Data for $\mathrm{I}_{\mathrm{ON}}$ and $\mathrm{I}_{\mathrm{OFF}}$ was used to identify which structure has the best MOSFET performance, best MOSFET structure performance was obtained when $\mathrm{I}_{\mathrm{OFF}}=0$ and has higher value of $\mathrm{I}_{\mathrm{ON}}$. Equation (1) show the relationship between dielectric constant, $k$ and oxide thickness, $t_{o x}$ [12]. Smaller $k$ with smaller $t_{o x}$ produce larger capacitance hence higher in device leakage current, IOFF . It is undesirable to have high I $_{\mathrm{OFF}}$ because high-power consumption and decreases the efficiency of the system. High $\mathrm{I}_{\mathrm{ON}}$ was needed to control process of charge and discharge the circuit and it can be used for fast switching device[2].

$$
\frac{C_{o x}}{A}=\frac{k \times \varepsilon_{o}}{t_{o x}}
$$

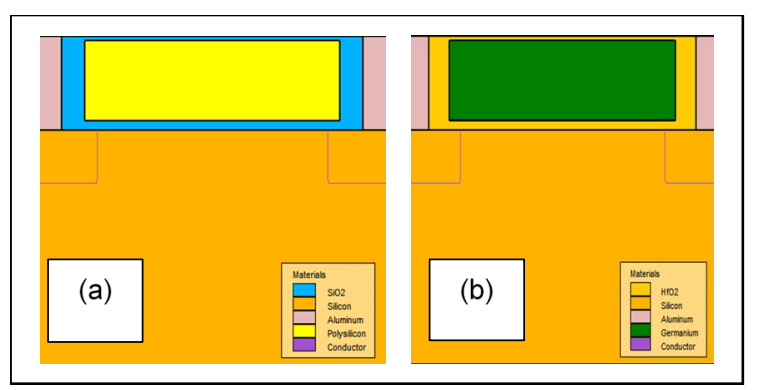

Fig. 2. MOSFET structure with (a) $\mathrm{SiO}_{2}$ and polySi as dielectricand gate material (b) ) $\mathrm{HfO}_{2}$ and $\mathrm{Ge}$ as dielectric and gate material.

Figure 3 shows $I_{D}-V_{G}$ graph for MOSFET with different dielectric material. It shows that $\mathrm{HfO}_{2}$ has larger value of $\mathrm{I}_{\mathrm{ON}} \sim$ $60.5 \times 10^{-6} \mathrm{~A} / \mathrm{um}$ and low $\mathrm{I}_{\mathrm{OFF}} \sim 92.4 \times 10^{-12} \mathrm{~A} / \mathrm{um}$ when compared to $\mathrm{SiO}_{2}$ with $\mathrm{I}_{\mathrm{ON}}$ of $21.5 \times 10^{-6} \mathrm{~A} / \mathrm{um}$ and $\mathrm{I}_{\mathrm{OFF}}$ of 0.126 $\mathrm{x} 10^{-9} \mathrm{~A} / \mathrm{um}$. This result proved that using $\mathrm{HfO}_{2}$ as dielectric material can increased the MOSFET performance because it has higher value of $\mathrm{I}_{\mathrm{ON}}$ and low value of $\mathrm{I}_{\mathrm{OFF}}$ due to high value of $k$ even though it has low mobility.

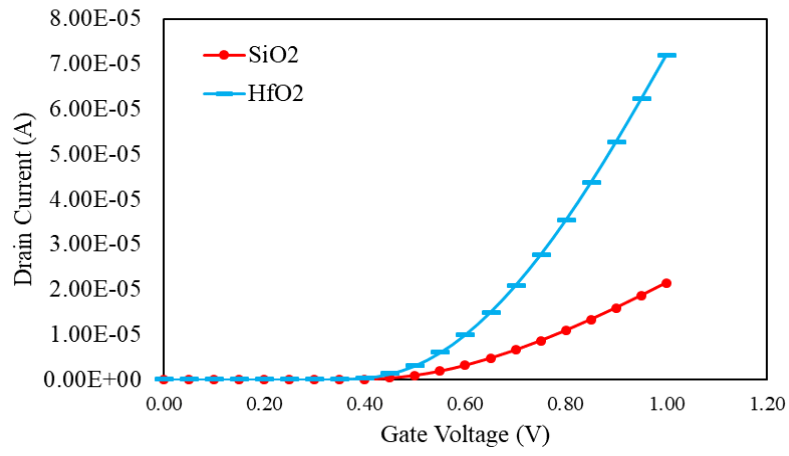

Fig. 3. $\mathrm{I}_{\mathrm{D}}-\mathrm{V}_{\mathrm{D}}$ graph for MOSFET structure with $\mathrm{SiO}_{2}$ and $\mathrm{HfO}_{2}$ as dielectric material.

\section{B. Fabrication of MOSFET using different gate material}

The purpose of simulating MOSFET with different gate material is to enhance the lower mobility that occur in the MOSFET structure with $\mathrm{SiO}_{2}$ and $\mathrm{HfO}_{2}$. Patiya et.al stated that material with lower energy band gap are capable to boost the mobility of a device. Higher mobility device has less leakage current and smaller subthreshold voltage, subvt [9].

Figure 4 show the comparison of $\mathrm{I}_{\mathrm{D}}-\mathrm{V}_{\mathrm{G}}$ graph MOSFET with $\mathrm{HfO}_{2}$ as dielectric and polysilicon and $\mathrm{Ge}$ as gate material. MOSFET with Ge has IOFF of $6.94 \times 10^{-11} \mathrm{~A} / \mathrm{um}$ and $\mathrm{I}_{\mathrm{ON}}$ is 1.63 x $10^{-6} \mathrm{~A}$ /um. While MOSFET with polysilicon has I IFF of $1.2 \mathrm{x}$ $10^{-10} \mathrm{~A} / \mathrm{um}$ and $\mathrm{I}_{\mathrm{ON}}$ is $7.19 \times 10^{-5} \mathrm{~A} / \mathrm{um}$. From the result show that MOSFET with Ge has reduced leakage current by a factor of 0.58 . This result proved that using $\mathrm{Ge}$ as gate material enhance the MOSFET performance because Ge serves as a carrier and can pack in more electrons than polysilicon [9, 13]. It also concludes that $\mathrm{HfO}_{2}$ and $\mathrm{Ge}$ are having good MOSFET performance.

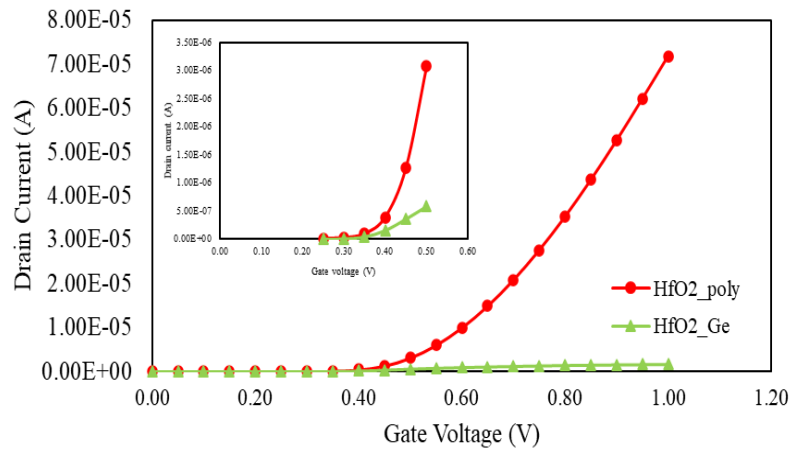

Fig. 4. Comparison of $\mathrm{I}_{\mathrm{D}}-\mathrm{V}_{\mathrm{G}}$ graph for MOSFET structure with $\mathrm{HfO}_{2}$ as dielectric and PolySi and $\mathrm{Ge}$ as gate material.

\section{Effect of Oxide Thickness}

Oxide thickness, $t_{o x}$ also play important role in determine the MOSFET performance. Equation (1) and (2) show the relationship between $t_{o x}$ and $\mathrm{V}_{\text {th }}$. The device with thinner oxide layer has higher I $\mathrm{ON}_{\mathrm{N}}$ and it has lower gate control for the process of turning "on and off" of the device [16]. It also shows better interface layer between dielectric and gate material and hence improve the performance of the transistor [14].

Leakage current, $I_{O F F}$ can be obtained from the $I_{D}-V_{G}$ graph which is at low drain voltage, $\mathrm{V}_{\mathrm{D}}$. Leakage current was triggered by the charging tunneling of the traps in the interface between oxides and the semiconductor [15]. IOFF become higher due to weak inversion state leakage that is a function of $\mathrm{V}_{\mathrm{th}}$.

$$
I_{D}=\frac{1}{2} \mu C_{o x} \frac{W}{L}\left(V_{G}-V_{T}\right)^{2}
$$


Figure 5 and fig. 6 illustrates the thickness of oxide layer that was vary from 5 to $15 \mathrm{~nm}$ for both MOSFET structure. Figure 7 show the $\mathrm{I}_{\mathrm{D}}-\mathrm{V}_{\mathrm{G}}$ graph of MOSFET when $t_{o x}$ at $5 \mathrm{~nm}$.

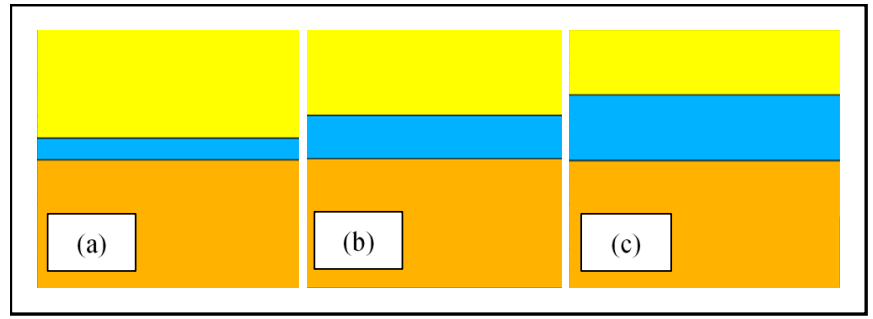

Fig. $5.1^{\text {st }}$ MOSFET structure with variation of oxide thickness (a) $5 \mathrm{~nm}$ (b) $10 \mathrm{~nm}$ (c) $15 \mathrm{~nm}$

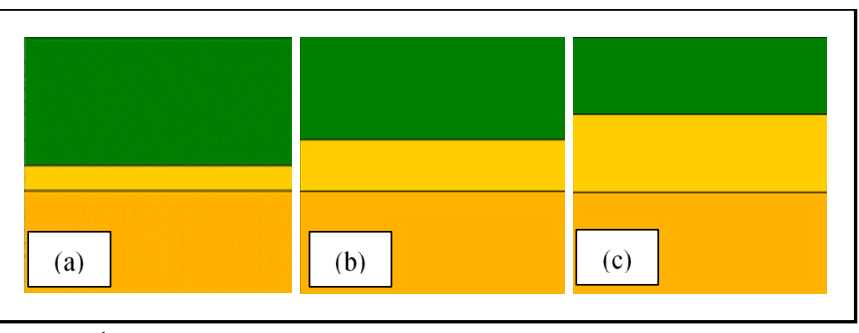

Fig. $6.2^{\text {nd }}$ MOSFET structure with variation of oxide thickness (a) $5 \mathrm{~nm}$ (b) $10 \mathrm{~nm}$ (c) $15 \mathrm{~nm}$

$\mathrm{I}_{\mathrm{OFF}}$ can be reduced by reducing subvt as reducing $t_{o x}$ will decrease $C_{o x}$ hence subvt is lower. Subvt was defined by using Eq. (3). If $V_{G}$ is under $V_{\text {th }}$, the transistor flows into the subvt region with a very tiny current[3]. Fast switching device was obtained on a device with lower subvt [10]. High-k material has acceptable ION that reduce subvt. Subvt determines how much gate voltage swing that is needed to change the current onedecade, based on the result obtained in Table 3, the value is around $70 \sim 100 \mathrm{mV} /$ decade[3]. Thus, $\mathrm{HfO}_{2}$ was fast switching device that has smallest subvt value as compared to $\mathrm{SiO}_{2}$.

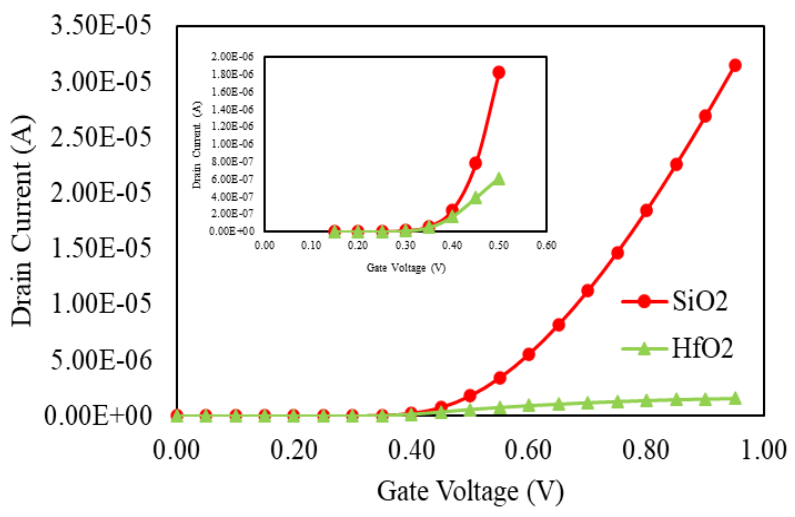

Fig. 7. $I_{D}-V_{D}$ graph for oxide thickness at $5 \mathrm{~nm}$

Table 4 show the comparison of I-V data when $t_{o x}$ is varies. Thicker oxide layer affect increasing in $\mathrm{V}_{\mathrm{GS}}$ and increase IOFF. Besides, it also proves that the $\mathrm{V}_{\text {th }}$ value will increase as $\mathrm{t}_{\mathrm{ox}}$ increase.
TABLE IV

COMPARISON OF MOSFET PERFROMANCE WHEN OXIDE THICKNESS VARIES

\begin{tabular}{|c|c|c|c|c|c|c|}
\hline & \multicolumn{4}{|c|}{$\mathrm{SiO}_{2}$} & \multicolumn{2}{|c|}{$\mathrm{HFO}_{2}$} \\
\hline $\mathrm{t}_{\mathrm{ox}}(\mathrm{nm})$ & 5 & 10 & 15 & 5 & 10 & 15 \\
\hline $\mathrm{V}_{\text {th }}(\mathrm{V})$ & 0.361 & 0.365 & 0.377 & 0.114 & 0.119 & 0.124 \\
\hline $\begin{array}{l}\text { Subvt } \\
(\mathrm{mV} / \mathrm{de} \\
\mathrm{c})\end{array}$ & 0.076 & 0.081 & 0.086 & 0.074 & 0.075 & 0.076 \\
\hline $\begin{array}{l}\text { I } \\
\left(\mathrm{xN} 10^{-6}\right. \\
\mathrm{A} / \mathrm{cm})\end{array}$ & 36.1 & 21.5 & 15.1 & 1.66 & 1.63 & 1.61 \\
\hline $\begin{array}{l}\mathrm{I}_{\mathrm{OFF}} \\
\left(\mathrm{x} 10^{-12}\right. \\
\mathrm{A} / \mathrm{cm})\end{array}$ & 122 & 126 & 128 & 68.8 & 69.4 & 70.1 \\
\hline $\begin{array}{l}\mathrm{I}_{\mathrm{ON}} / \mathrm{I}_{\mathrm{OFF}} \\
\left(\mathrm{x} 10^{6}\right)\end{array}$ & 0.295 & 0.171 & 0.118 & 0.024 & 0.023 & 0.023 \\
\hline
\end{tabular}

\section{Effect of Channel Length}

Channel length is directly proportional with $V_{t h}$. When $\mathrm{V}_{\text {th }}$ drop too much, I IFF become too large and $L_{g}$ will turned to unacceptable value. Theoretical, by decreasing $\mathrm{Lg}$, the saturation drain current will increase.

In this study, $L_{g}$ was varied from $0.5 \mathrm{um}, 0.8 \mathrm{um}$ and $1.0 \mathrm{um}$ to obtain the optimized $L_{g}$ with good performance MOSFET. Figure 8 and fig. 9 shows the comparison $\mathrm{I}_{\mathrm{D}}-\mathrm{V}_{\mathrm{G}}$ for MOSFET with $\mathrm{SiO}_{2}$ and $\mathrm{HfO}_{2}$ when $L_{g}$ is varies. Reducing $L_{g}$, increased the saturation drain current, IDS and reducing the $V_{t h}$ value. As $V_{\text {th }}$ was reduced, distance for drain to source and drain to channel also reduced. $L_{g}$ with $0.8 \mathrm{um}$ show the best optimized data for MOSFET fabricate with $\mathrm{SiO}_{2}$ and $\mathrm{HfO}_{2}$. Figure 10 show the comparison graph of $\mathrm{I}_{\mathrm{D}}-\mathrm{V}_{\mathrm{G}}$ for MOSFET with $\mathrm{SiO}_{2}$ and $\mathrm{HfO}_{2}$ at $L_{\mathrm{g}}$ of $0.8 \mathrm{um}$.

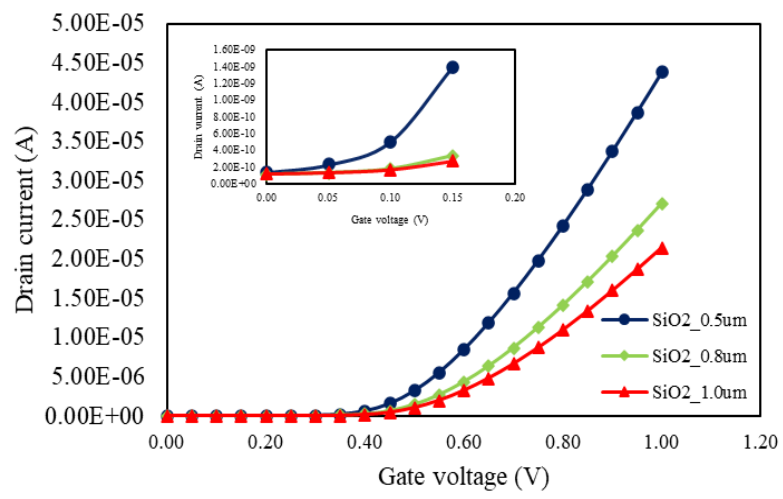

Fig. 8. MOSFET structure with $\mathrm{SiO}_{2}$ when channel length is varies.

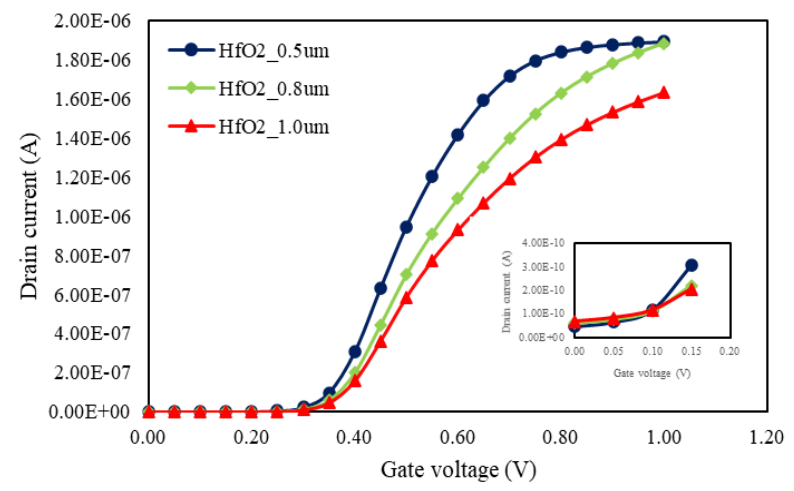

Fig. 9. MOSFET structure with $\mathrm{HfO}_{2}$ when channel length is varies 


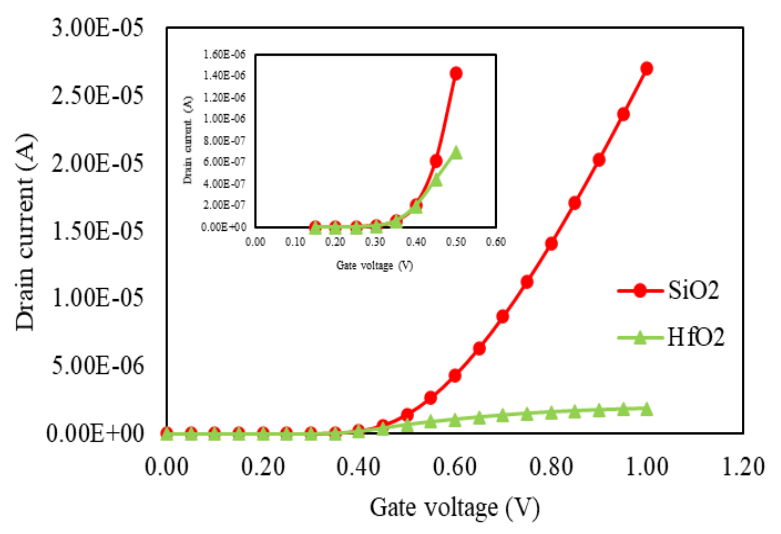

Fig. 10. Comparison of $\mathrm{I}_{\mathrm{D}}-\mathrm{V}_{\mathrm{D}}$ graph for $\mathrm{SiO}_{2}$ and $\mathrm{HfO}_{2}$ at $L_{g}$ is $0.8 \mathrm{um}$

Figure 11 and fig.12 illustrates $\mathrm{I}_{\mathrm{D}}-\mathrm{V}_{\mathrm{G}}$ graph when $L_{g}$ was varied for MOSFET structure using $\mathrm{SiO}_{2}$ and $\mathrm{HfO}_{2}$ respectively. From this graph, it clearly shows linear and saturation region. As $L_{g}$ decreased, distance between drain and source and drain to channel are also reduce. Modulation of the $L_{g}$ ensures that the saturation region marginally decreases as the drain to source voltage rises. Both $\mathrm{I}_{\mathrm{D}}-\mathrm{V}_{\mathrm{D}}$ graph for MOSFET with $\mathrm{SiO}_{2}$ and $\mathrm{HfO}_{2}$, it clearly shows that both device with shorter channel suffers more from channel modulation effect [18]. MOSFET with $\mathrm{HfO}_{2}$ and $\mathrm{Ge}$ has lower channel length modulation effect as compare to MOSFET with $\mathrm{SiO}_{2}$ and polysilicon.

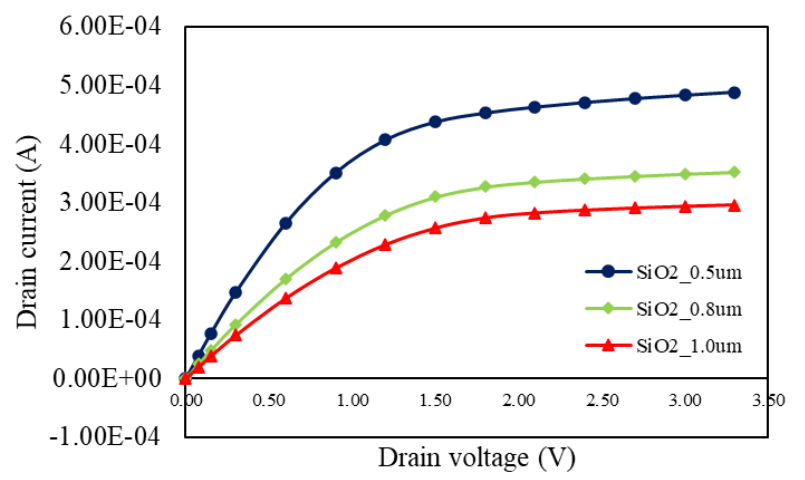

Fig. 11. $\mathrm{I}_{\mathrm{D}}-\mathrm{V}_{\mathrm{D}}$ for MOSFET structure with $\mathrm{SiO}_{2}$ when channel length is varies

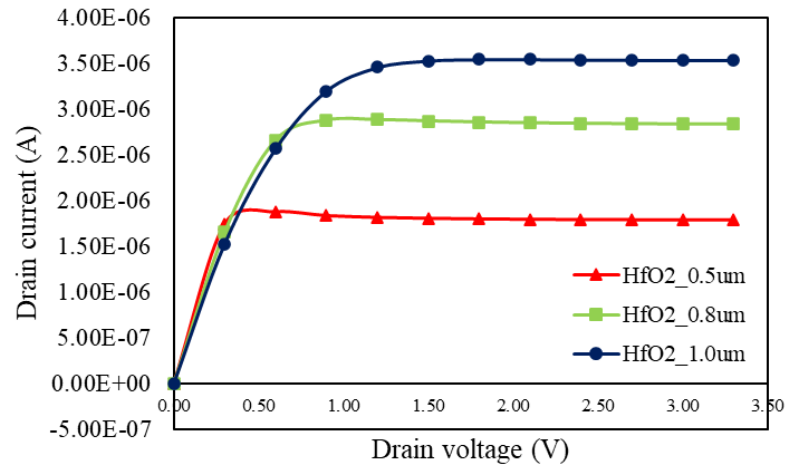

Fig. 12. $\mathrm{I}_{D}-\mathrm{V}_{\mathrm{D}}$ MOSFET structure with $\mathrm{HfO}_{2}$ when channel length is varies.
Gate material engineering increase surface potential in the channel at the contact of two metals which makes the field to reallocate at the drain end [18]. According to Fig. 12, the drain bias voltage, $V_{D}$ has no significant effect on the inversion layer hence no channel length modulation effect is observed in the device structure [18]. Reducing the $L_{g}$ width affect $V_{t h}$ and IoFF because both was modulated by the width.

The variation of $\mathrm{Lg}_{\mathrm{g}}$ was fabricate and the data has been recorded in Table 5. Table 5 illustrate the comparison reading for $\mathrm{SiO}_{2}$ and $\mathrm{HfO}_{2}$ where shorter gate length has highest $\mathrm{I}_{\mathrm{OFF}}$ for $\mathrm{SiO} 2$ structure while for shorter gate length of $\mathrm{HfO}_{2}$ structure has smallest $\mathrm{I}_{\mathrm{OFF}}$. Besides, it also shows that the present of high$\mathrm{k}$ material and lower energy bandgap of metal has changed device performance. High-k device has lower $\mathrm{I}_{\mathrm{OFF}}$, smaller $\mathrm{V}_{\text {th }}$ and smaller subvt. Thus, SCEs was control by using $\mathrm{HfO}_{2}$ as dielectric gate and $\mathrm{Ge}$ as gate. The relationship between $L_{g}$ and $\mathrm{V}_{\text {th }}$ shows that, shorter $L_{g}$ affect smallest value of $\mathrm{V}_{\text {th }}$. The charge in depletion region was support by drain and source. Meanwhile, charge support in gate region decrease and it reduce $\mathrm{V}_{\text {th }}$ value. $\mathrm{V}_{\text {th }}$ decrease with reduction in $L_{g}$ hence reduce subvt. On the other hand, the relationship between $L_{g}$, I IFF $_{\text {for }}$ $\mathrm{SiO}_{2}$ structure indicates that the shorter the channel length, it has higher $\mathrm{I}_{\mathrm{OFF}}$. The short MOSFET channel required lower energy supply to reduce electrical domains internally and power consumption [13]. A smallest $\mathrm{I}_{\mathrm{OFF}}$ should be maintained to minimize the static power of a circuit. Shrinking the channel length on $\mathrm{HfO}_{2}$ MOSFET has smaller I IFF compare to $\mathrm{SiO}_{2}$.

TABLE V

Comparison of Mosfet Perfromance when Channel Length Varies

\begin{tabular}{|c|c|c|c|c|c|c|}
\hline & \multicolumn{4}{|c|}{$\overline{\mathrm{SiO}_{2}}$} & \multicolumn{2}{|c|}{$\mathrm{HFO}_{2}$} \\
\hline $\begin{array}{l}\mathrm{Lg} \\
(\mathrm{nm})\end{array}$ & 0.5 & 0.8 & 1.0 & 0.5 & 0.8 & 1.0 \\
\hline$V_{\text {th }}(\mathrm{V})$ & 0.3207 & 0.3548 & 0.3654 & 0.1029 & 0.1133 & 0.1191 \\
\hline $\begin{array}{l}\text { Subvt } \\
(\mathrm{mV} / \mathrm{de} \\
\mathrm{c})\end{array}$ & 0.0905 & 0.0823 & 0.0809 & 0.0753 & 0.0747 & 0.0750 \\
\hline $\begin{array}{l}\mathrm{I}_{\mathrm{ON}} \\
\left(\mathrm{x} 10^{-6}\right. \\
\mathrm{A} / \mathrm{cm})\end{array}$ & 43.8 & 27 & 21.5 & 1.89 & 1.88 & 1.63 \\
\hline $\begin{array}{l}\mathrm{I}_{\mathrm{OFF}} \\
\text { (x10 } \\
\mathrm{A} / \mathrm{cm})\end{array}$ & 144 & 115 & 126 & 48.6 & 61.6 & 69.4 \\
\hline $\begin{array}{l}\mathrm{I}_{\mathrm{ON}} / \mathrm{I}_{\mathrm{OFF}} \\
\left(\mathrm{x} 10^{6}\right)\end{array}$ & 0.311 & 0.235 & 0.171 & 0.0389 & 0.0305 & 0.0235 \\
\hline
\end{tabular}

\section{CONCLUSION}

MOSFET structure was successfully design in Silvaco TCAD tool using different type of high-k dielectric material. Fast switching device need higher value of $\mathrm{I}_{\mathrm{ON}}$ and it can be obtained from $\mathrm{HfO}_{2}$ structure that has dielectric constant $\mathrm{k}=22$ bigger than $\mathrm{SiO}_{2}$ with $\mathrm{k}=3.9$. Hence, $\mathrm{HfO}_{2}$ was choose as new dielectric material that qualified to reduce SCEs. The variation of polysilicon and Ge able to control SCEs due to a decrement in leakage current by a factor of 0.55 . On the other hand, thinner oxide layer and shorter gate length lead to SCEs. Reducing the size of structure can still enhance MOSFET performance in $V_{\text {th }}$, IOFF and I-V characteristics. This is because SCEs was reduced in $\mathrm{HfO}_{2}$ structure and the result show it has smaller $\mathrm{V}_{\text {th }}$ and $\mathrm{I}_{\mathrm{OFF}}$ in comparisons with conventional structure. Therefore, material 
with high-k material such as $\mathrm{HfO}_{2}$ is suitable to combine with lower energy bandgap metal, Ge to produce smaller size of MOSFET with high efficiency performance. This proved that material with highest dielectric constant than $\mathrm{HfO}_{2}$ and metal with lower energy bandgap are suggested for future study as it can reduce SCEs.

\section{ACKNOWLEDGMENT}

The author like to express their gratitudes to UiTM Cawangan Pulau Pinang for providing the funding, laboratory facilities and technical support.

\section{REFERENCES}

[1] V. M. S. a. G. S. Himangi Sood, "Advanced MOSFET Technologies for Next Generation Communication Systems - Perspective and Challenges: A Review," Journal of Engineering Science and Technology Review, pp. 180-195, 19 July 2018.

[2] A. Sarkar, "Short Channel Effects (SCes) in sub-100nm MOSFET: A Review," IEW, India: CRC Press, 2016.

[3] C. H. J. W. E. D. N. K. N. a. C. H. Bin Yu, "Short-Channel Effect Improved by Lateral Channel Engineering in Deep-Submicronmeter MOSFET's," IEEE Transactions on Electron Devices, vol. 44, no. 4, pp. 627-634, April 1997.

[4] S. D. a. A. S. Sakshi, "Analyzing the effect of gate dielectric on the leakage currents," in MATEC Web Conferences, India, 2016.

[5] J. W. B. Majkusiak, Theoretical limit for the $\mathrm{SiO} 2$ thickness in silicon MOS devices, Poland: Kluwer Academic Publisher, 2016

[6] I. B. A. a. B. B. Y. M. Norani Bt. Atan, "Effect og high-k dielectric with metal gate for electrical characteristics of $18 \mathrm{~nm}$ NMOS device," IEEEICSE2014, Kuala Lumpur, Malaysia, 2014.

[7] S. D. a. a. S. Sakshi, "Analyzing the effect of gate dielectric on the leakage currents," in MATEC web confferences, India, 2016

[8] A. p. N. a. D. U. C. Nelsa Abraham, "Modeling and Simulation Studies of 22nm Multigate bulk FinFET Structures with Different Dielectric Materials," International Journal of Electronics Engineering Research., vol. 9, no. 2, pp. 255-266, 2017

[9] R. D. a. N. Patiya, "Electrical Characteristics Assessment on Heterojunction Tunnel FET (HTFET) by Optimizing Various High-k Material: $\mathrm{HfO} 2 / \mathrm{ZrO} 2, "$ International Journal of Innovative Technology and Exploring Engineering (IJITEE), vol. 8, no. 10, pp. 2278-3075, 2019.

[10] M. K. A. N. P. S. E. U. S. S. H. Ceric, "Vista status report December 2005," Institute for Microelectronics Technical Vienna, Australia, 2005.

[11] M. S. I. K. R. Y. Ray Duffy, "Germanium Doping Challenges," in 13th International Workshop on Junction Technology 2013, Ireland, 2013

[12] R. N. Vaidotas Barzdenas, Microtechnologies, Vilnius: Vilnius Technika, 2017.

[13] Z. N. K. a. S. A. Khan, "Incorporation of Ge on High K Dielectric Material for Different," Journal of Nanomaterials, vol. 2018, no. 2497352, pp. 17, 2018.

[14] S. M. a. H. M. M. Kaushik Roy, "Leakage Curent in Deep Submicron CMOS Circuits," Journal od Circuits, Systems and Computers, vol. 11, no. 6, pp. 1-26, 2002.

[15] D. D. \&. H. H. Mohammad Karbalaei, "Impact of high-k gate dielectric with different angles of coverage on the electrical characteristics of gate all around field effect transistor: a simulation study," Journal Pre-proofs, vol. 16, no. 102823, pp. 1-17, 2019

[16] J.-C. F. a. S.-F. Lee, "Effect of oxide layer in metal oxide semmiconductor sytem," in MATEC Web of Conferences, Taiwan, 2016.

[17] G. T. a. K. Ghosh, "Theoretical analysis and optimization of high-k dielectric layers for designing high-performance and low-power-dissipation nanoscale double-gate MOSFETs," Journal of Computational Electronics, vol. 18, no. 15, pp. 924-940, 2019.

[18] J. Westlinder, "Investigation of Novel Metal Gate and High-k Dielectric Materials for CMOS Technologies," Acta Universitatis Upsaliensis, pp. 1-72, 2004.

[19] K. A. E. T. E. C. a. W. S. Matthew Merry, "Optimization of device performance using semiconductor TCAD tools," Silvaco.com, Michigan, 2001.

[20] N. V. A. K. A. R. A. M. Bhanu chandar D, "Suppression of short channel effect (SCEs) by dual material gate vertical surrounding gate (DMGVSG)
MOSFET: 3-D TCAD Simulation," in International conference on design and manufacturing, India, 2013 